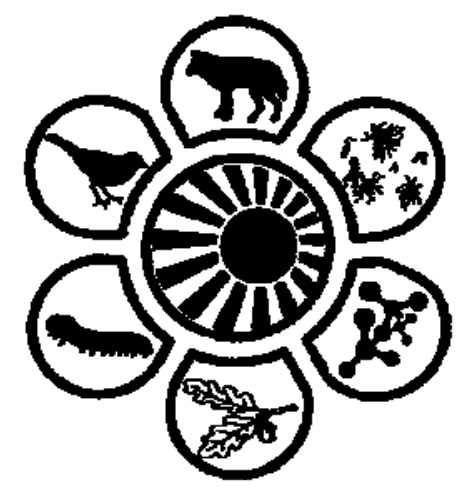

Вісник Дніпропетровського університету. Біологія, екологія.

Vìsnik Dnìpropetrovs'kogo unìversitetu. Seriâ Bìologiâ, ekologiâ

Visnyk of Dnipropetrovsk University. Biology, ecology.

Vìsn. Dnìpropetr. Unìv. Ser. Bìol. Ekol. 2014. 22(2), 115-121.

doi: $10.15421 / 011417$

ISSN 2310-0842 print

ISSN 2312-301X online

www.ecology.dp.ua

\title{
Терміни розмноження та розмір кладки у Parus major та $P$. caeruleus у Харківській та Сумській областях
}

\author{
Д.І. Бондарець, А.Б. Чаплигіна \\ Харківський національний педагогічний університет імені Г.С. Сковороди, Харків, Украйна
}

\begin{abstract}
Синиці починають нестися за умови стійкого переходу середньодобової температури через $+4{ }^{\circ} \mathrm{C}$. У синиці великої та синиці блакитної в умовах НПП «Гомільшанські ліси» максимальна кількість розпочатих кладок (середній розмір $12,3 \pm 1,50$ та $12,8 \pm$ 1,75 яйця відповідно) спостерігається за $+15^{\circ} \mathrm{C}$, зі зростанням якої розмір кладки поступово зменшується. Виявлено розмір повних кладок синиці великої $(\mathrm{n}=164)$ та синиці блакитної $(\mathrm{n}=38)$ у Сумській та Харківській областях. У синиці великої він варіює від 5 до 15 яєць, що у середньому становить в умовах НПП «Гомільшанські ліси» (ділянка 1) 10,8 \pm 1,93, в ур. Вакалівщина (ділянка 2) $9,3 \pm 2,33$ та у НПП «Гетьманський» (ділянка 3 ) - 9,1 $\pm 2,28$, а у синиці блакитної - від 5 до 15 яєць, що у середньому становить $11,4 \pm 2,09$ (1), 9,3 $\pm 2,81$ (2) та 10,5 (3) відповідно. Встановлено розмір кладок для синиці великої та синиці блакитної, який зустрічається найчастіше на кожній ділянці. У синиці великої найбільшу частку складають 11 -яйцеві кладки $(10,9 \%)(1), 11$-яйцеві кладки (12,7\%) (2), 9- та 10-яйцеві кладки (по 3,0\%) (3). У гніздах синиці блакитної найчастіше зустрічаються 12-яйцеві кладки (21,1\%) (1), на ділянках 2 та 3 не виявлено розмір кладки, який би переважав. Найбільшу кількість кладок синиця велика розпочала у другій декаді квітня $(\mathrm{n}=28)(1)$ та у першій декаді травня $(\mathrm{n}=25)(2)$, а синиці блакитні приступили до відкладання яєць у третій декаді квітня (n=17) (1), у першій $(\mathrm{n}=2)$ та другій $(\mathrm{n}=2)$ декадах травня (2). У НПП «Гетьманський» перевана кількість кладок синицею великою та синицею блакитною розпочата в третій декаді квітня.
\end{abstract}

Ключові слова: синиця велика; синиця блакитна; розмір кладки; терміни розмноження

\section{Timing of reproduction and clutch size in Parus major and P. caeruleus in Kharkiv and Sumy regions}

\author{
D. Bondarets, A. Chaplygina \\ G.S. Skovoroda Kharkiv National Pedagogical University, Kharkiv, Ukraine
}

Under our supervision were on average 450 artificial nesting in different years. Studies were conducted in 2006-2014 in the conditions of oak forest in national natural park "Homilshanski forests" (Kharkiv region) ( $49^{\circ} 38^{\prime}$ north latitude, $36^{\circ} 18^{\prime}$ east longitude), pine forests in National natural park "Hetmansky" (50 $22^{\prime}$ north latitude, $35^{\circ} 01^{\prime}$ east longitude) and broadleaf forest natural boundary Vakalivschyna (Sumy region) $\left(51^{\circ} 01^{\prime}\right.$ north latitude, $34^{\circ} 55^{\prime}$ east longitude). We investigated 164 layings of great tits and 38 laying of blue tits. Terms of breeding of birds were determined by the date of laying of the first egg. It was found that tits began to lay eggs at steady transition of the average daily temperature over $+4^{\circ} \mathrm{C}$. Maximum amount of started layings was observed in great tits and blue tits in the conditions of the national natural park "Homilshanski forests" (average size $-12.3 \pm 1.50$ and $12.8 \pm 1.75$ eggs, respectively) at $+15{ }^{\circ} \mathrm{C}$, with the size of laying gradually decreasing with higher temperatures. Sizes of full layings in great tits $(\mathrm{n}=164)$ and blue tits $(\mathrm{n}=38)$ in Sumy and Kharkiv regions were found. With regard to the great tit, it varies from 5 to 15 eggs being on average $10.8 \pm 1.93$ in the conditions of NNP "Homilshanski forests", at natural boundary Vakalivschyna $-9.3 \pm 2.33$ and at NNP "Hetmansky" $-9.1 \pm 2.28$, while for blue tits it is equal to 5-15 eggs, i.e. $11.4 \pm$ 2.09 on average in the conditions of NNP "Homilshanski forests", at natural boundary Vakalivschyna $-9.3 \pm 2.81$ and at NNP "Hetmansky" 10.5. Size of laying for great tits and blue tits, which prevails for each territory, has been established. The largest sizes for great tits are: 11-egg laying (10.9\%) in the conditions of NNP "Homilshanski forests", 11-egg laying (12.7\%) dominating at the natural boundary Vakalivschyna and 9- and 10-egg laying (by 3.0\%) at NNP "Hetmansky". 12-egg laying (21.0\%) was often found in the nests of blue tits in conditions of NNP "Homilshanski forests", size of laying which would be dominating in blue tits at the natural boudary Vakalivschyna and NNP "Hetmansky" was not found. The largest number of laying by great tits was started at NNP "Homilshanski forests" in the second decade of

Харківський національний педагогічний університет імені Г.С.Сковороди, вул. Артема, 29, Харків, 61002, Украӥна G.S. Skovoroda Kharkiv National Pedagogical University, Artema Str., 29, Kharkiv, 61002, Ukraine

Teл.: +38-050-618-18-96, E-mail: iturdus@ukr.net 
April $(\mathrm{n}=28)$, at natural boundary Vakalivschyna - in early May $(\mathrm{n}=25)$, while blue tits started laying eggs at NNP "Homilshanski forests" in the third decade of April $(n=17)$, at natural boundary Vakalivschyna - in the first $(n=2)$ and second $(n=2)$ week in May. Overwhelming number of layings were started by great tits and blue tits at NNP "Hetmansky" in the third week of April.

Keywords: great tit; blue tit; clutch size; timing of reproduction

\section{Вступ}

Ефективність розмноження птахів значною мірою визначає розмір кладки, який залежить від впливу різних факторів (Daan et al., 1990). Зі збільшенням широти відбувається зростання розміру кладки (Cardillo, 2002). У птахів-дуплогніздників кількість яєць у кладці можуть визначати параметри гніздівлі (Soler et al. 2001; Møller et al., 2014a, 2014b, 2014c), генотип самок, їх фенотипічна пластичність (Haywood, 2013) і строки розмноження птаxiв (Lepage, 2000; Christians et al., 2001; Tinbergen and Williams, 2002; Boulton, 2012). Наприкінці періоду гніздування перші кладки Pica pica (Linnaeus, 1758) можуть мати низьку фенотипічну якість (De Neve, 2004). Суперечлива інформація стосовно кількості яєць у повторних кладках. Одні дослідники описують зменшення розміру кладки, що свідчить про зниження репродуктивної функції самок протягом сезону розмноження (Hansson et al., 2000; Nilsson, 2000). Інші автори вважають, що витрати на продукування яєць є незначними: з'ясовано, що після видалення яєць із кладок куликів птахи здатні відкладати значно більше яєць (Grønstøl et al., 2006). Проте інкубація незвично великих кладок може вплинути на продуктивність після вилуплення пташенят та спричинити нижчу річну успішність розмноження у куликів (Lengyel et al., 2009).

На розмір кладки впливають сезонні коливання доступності кормових ресурсів (Clifford, 2001; Yom-Tov and Geffen, 2002). У популяціях чоботаря (Recurvirostra avosetta Linnaeus, 1758) кількість молоді позитивно пов'язана 3 наявністю достатньої кількості корму для іiі вирощування. Цікаво, що останні краще виживають у великих виводках (Lengyel, 2007). Проте у шпака (Sturnus vulgaris Linnaeus, 1758) додатковий корм і температура навколишнього середовища не мають статистично значимого впливу на кількість яєць у кладці (Christians, 2000; Christian, 2002). Деякі автори вважають, що остаточну роль в еволюції розміру кладок має наявність кальцію у середовищі (Patten, 2007). Крім того, відомо, що зростання тиску хижаків викликає збільшення розміру кладок (Griebeler, 2010).

У більшості публікацій показано взаємозв'язок розміру кладки 3 параметрами яєць, які залежать від добової кількості енергії, доступної для їх формування (Schaper, 2013), строків і періодів розмноження (Nilsson, 2000). Безумовно, розмір яйця впливає на якість нащадків (Krist, 2011).

Завданням нашої роботи було проаналізувати хронологічну та сезонну мінливість розміру кладок синиці великої та синиці блакитної для підтримання сталості їх популяцій та охорони в умовах Лівобережної України.

\section{Матеріал і методи досліджень}

Дослідження проведені у 2006-2014 рр. в умовах діброви нагірного типу НПП «Гомільшанські ліси» (Харківська обл.) (49³8' пн. ш., 36²18' сх. д.), субору НПП
«Гетьманський» $\left(50^{\circ} 22^{\prime}\right.$ пн. ш., 3501' сх. д.) і широколистяного лісу ур. Вакалівщина (Сумська обл.) (5101' пн. ш., $34^{\circ} 55^{\prime}$ сх. д.). Для вказаних територій характерний помірно континентальний клімат, який формується в результаті взаємодії трьох основних факторів: сонячної радіації, циркуляції атмосфери та характеру підстилаючої поверхні. Як об’єкт досліджень обрано два види родини Paridae - синицю велику (Parus major Linnaeus, 1758) та синицю блакитну (P. caeruleus Linnaeus, 1758).

Під нашим спостереженням у різні роки перебувало в середньому 450 штучних гніздівель (120 шт. - НПП «Гомільшанські ліси», 200 шт. - ур. Вакалівщина, 130 шт. НПП «Гетьманський»). Їх перевірку здійснювали в період із I декади квітня по I декаду липня (у середньому до 10 разів). Штучні гніздівлі для малих горобцеподібних птахів мали стандартні розміри, були виготовлені 3 дощатого матеріалу 3 діаметром льотка 3 см. Кришка у таких гніздівель відкривається зверху або виймається спереду, що полегшує їх перевірку.

Досліджено 164 кладки синиці великої та 38 - синиці блакитної. Строки розмноження птахів визначали за датою відкладення першого яйця.

Під час розрахунку середніх температур повітря за роки дослідження використано щоденники погоди із сайту www.gismeteo.com. Статистичну обробку результатів проведено 3 використанням однофакторного дисперсійного аналізу (відмінності між середніми значеннями вважали вірогідними при $\mathrm{P}<0,05)$. У статті наведено середні значення та середньоквадратичне відхилення $(x \pm \mathrm{SD})$.

Дані з фенології синиць ур. Вакалівщина та НПП «Гетьманський» надані та уточнені М.П. Книшом, заступником директора 3 наукової роботи парку, якому автори щиро вдячні.

\section{Результати та їх обговорення}

У районі досліджень синиця велика та синиця блакитна $є$ кочовими, частково осілими, у більшості моноциклічними видами. По гніздових територіях синиці розподіляються у березні. На строки відкладання яєць впливає температурний режим навколишнього середовища, який визначає кормову базу птахів та фізіологічний стан самки у період формування яєць. Строки початку відкладання яєць у синиць залежать від середньодобової температури квітня, інколи - березня. За нашими підрахунками, синиці починають нестися за умови стійкого переходу середньодобової температури через $+4{ }^{\circ} \mathrm{C}$ (рис. 1). У теплі весни 2008, 2010 та 2014 рр. температура березня поступово збільшувалася, тому синиці після розподілу по територіях одразу почали будівництво гнізд та відкладання яєць. Аналіз залежності розміру кладок від середньодобової температури упродовж періоду відкладання яєць показав, що максимальна їх кількість в умовах НПП «Гомільшанські ліси» для синиці великої та синиці блакитної (середній 
розмір $12,3 \pm 1,50$ та $12,8 \pm 1,75$ яйця відповідно) спостерігається за $+15{ }^{\circ} \mathrm{C}$, зі зростанням якої розмір кладки поступово зменшується.

На території НПП «Гомільшанські ліси» у гніздах синиці великої перші яйця з'являються з II декади квітня (12.04.2008, 24.04.2009, 14.04.2010, 21.04.2011, 23.04.2012, 18.04.2013, 11.04.2014), що у середньому становить $18.04 \pm 5,3$ доби (11.04 у $2014-24.04$ у 2009 р.). Пік початку відкладання яєць у середньому за 7 років припадає на другу декаду квітня. У деяких особин зареєстровано повторні та другі кладки у III декаді травня - I декаді червня (24.05.2008; 01.06.2010; 02.06.2014), ïх відсоток незначний (табл. 4). Другі кладки властиві для незначної частини популяції синиць. Гніздування відбувається, як правило, у тих самих штучних гніздівлях. У 2014 році першу кладку птахи почали 11.04, другу кладку самка почала відкладати 23.05 в оновлене старе гніздо у тій самій штучній гніздівлі, чеpeз 3 доби після того, як пташенята його залишили. У синиці блакитної перші яйця з'являються у II декаді квітня - I декаді травня (11.04.2008, 17.04.2009, 19.04.2010, 03.05.2011, 27.04.2012, 21.04.2013, 17.04.2014), що у середньому становить - $20.04 \pm 6,0$ доби (11.04 у 2008 - 03.05 у 2011 р.). Повторні та другі кладки з'являються у I - III декадах травня (25.05.2008, 10.05.2013).
У Сумській області в урочищі «Вакалівщина» більшість кладок синиці великі починають у I декаді травня, але перші яйця у гніздах з'являються протягом II декади квітня - I декади червня (21.04.2006, 16.04.2007, 11.04 29.05.2008, 20.04-27.05.2009, 17.04-3.06.2010, 24.04.2011, 20.04-30.05.2012, 23.04.2013, 19.04.2014) (табл. 5). За 7 років спостережень перше яйце самки відкладають у середньому $19.04 \pm 3,9$ доби. У синиці блакитної в урочищі перші яйця реєструються 20.04.2007, 28.04.2009, 23.04.2012, 25.04.2013, 25.04.2014 р., що у середньому становить $-24.04 \pm 2,9$ доби (23.04 у 2012 - 31.05 у 2014 р.). В умовах НПП «Гетьманський» свіжі кладки синиці великої відмічені 24.04-6.06.2011, 14.04.2012, 21.04.2013 та 16.04.2014.

Існує широкий спектр змін розміру кладок птахів. Наприклад, у синиці великої він варіює від 1 до 17 яєць у кладці (Van Noordwijk et al., 1981; Воусе and Perrins, 1987). За нашими даними, розмір кладки достовірно збільшується з 9,1 $\pm 2,28(6-13 ; \mathrm{n}=22)$ у НПП «Гетьманський» та 9,3 $\pm 2,33(5-14 ; \mathrm{n}=94)$ в ур. Вакалівщина (табл. 2) до $10,8 \pm 1,93(5-15 ; \mathrm{n}=52)$ у НПП «Гомільшанські ліси» (табл. 1). Найбільшу частку в НПП «Гомільшанські ліси» та ур. Вакалівщина складають 11-яйцеві кладки, $10,9 \%$ та $12,7 \%$ відповідно. У НПП «Гетьманський» переважають 9- та 10-яйцеві кладки, по 3,0\% відповідно (рис. 2).

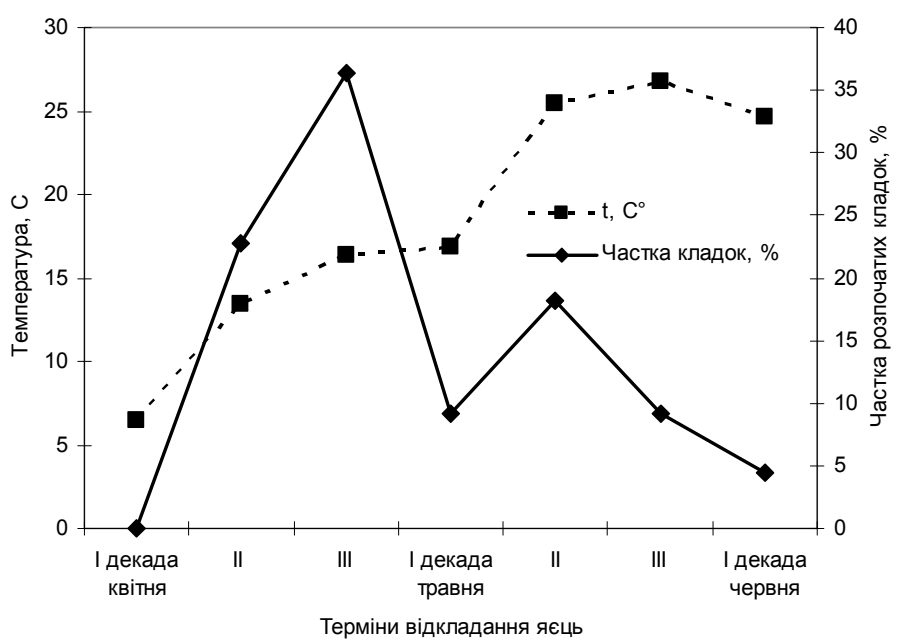

Рис. 1. Залежність частки відкладених яєць синиці великої від температури протягом періоду розмноження в НПП «Гомільшанські ліси» (2014 p.)

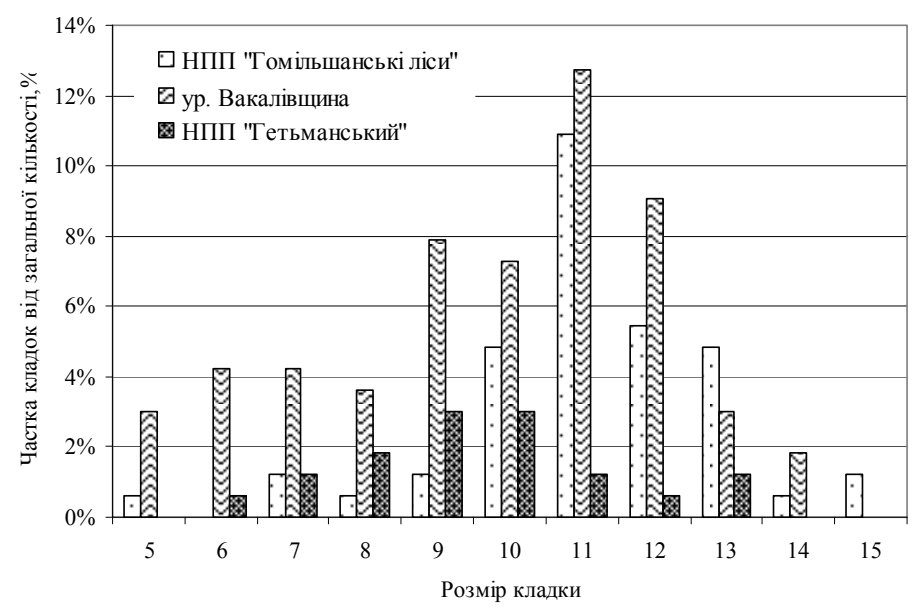

Рис. 2. Частка кладок різного розміру у синиці великої (n = 164) протягом 2006-2014 pp. 


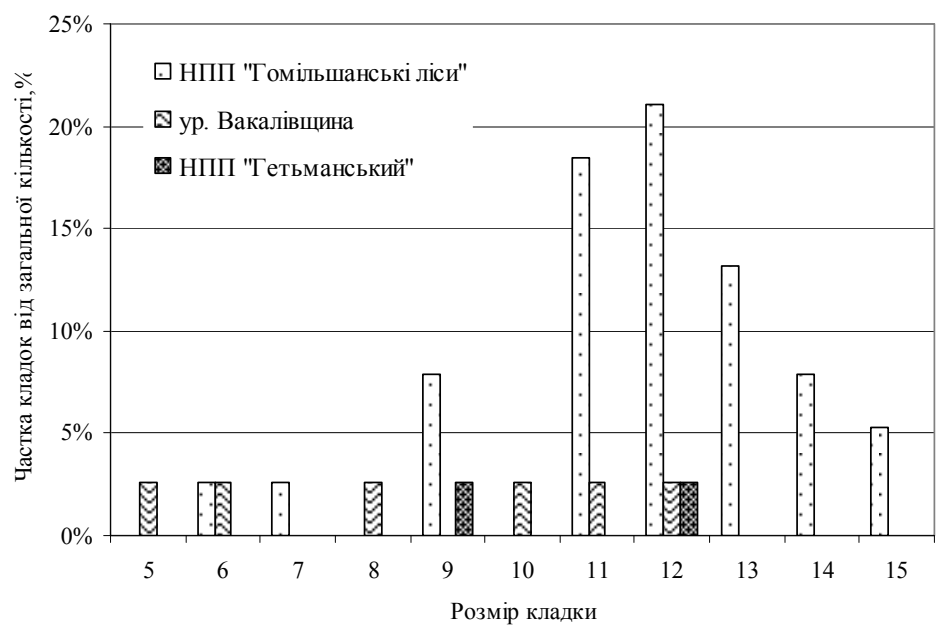

Рис. 3. Частка кладок різного розміру у синиці блакитної $(\mathbf{n}=38)$ протягом 2008-2014 pp.

У синиці блакитної розмір кладок варіює від 5 до 15 яєць у кладці. Аналіз показав, що розмір кладки достовірно збільшується з 9,3 $\pm 2,81(5-12 ; \mathrm{n}=6)$ в ур. Вакалівщина та $10,5(9-12 ; \mathrm{n}=2)$ у НПП «Гетьманський» до $11,4 \pm 2,09(6-15 ; \mathrm{n}=30)$ в НПП «Гомільшанські ліси» (табл. 1, 2). Найбільшу частку в НПП «Гомільшанські ліси» складають 12-яйцеві кладки $(21,1 \%)$. В ур. Вакалівщина та НПП «Гетьманський» розміру кладок, який би переважав, на даних територіях не виявлено (рис. 4).

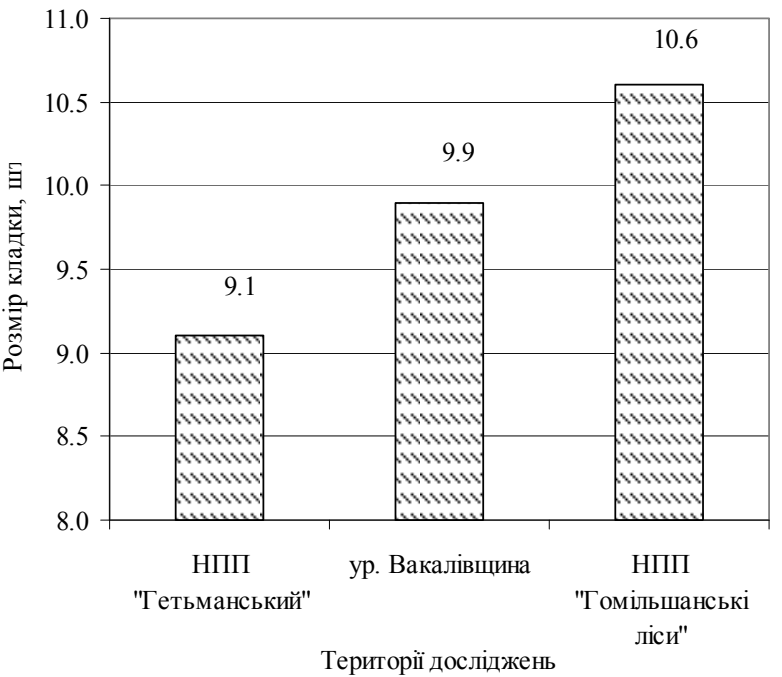

Рис. 4. Мінливість середнього розміру кладки синиці великої залежно від території дослідження (2014 р.)

Відома тенденція до збільшення розміру кладки зі збільшенням широти або з півночі на південь (Cardillo, 2002). За нашими даними, 3 просуванням на південь відбувається зростання середнього розміру кладок із $9,3 \pm$ $2,81(5-12 ; \mathrm{n}=6)$ в ур. Вакалівщина й до $11,4 \pm 2,09$ (6$15 ; \mathrm{n}=30)$ в НПП «Гомільшанські ліси» $(\mathrm{P}<0,01)$, хоча широтні відмінності можуть бути пом'якшені під впливом інших факторів: особливості біотопу, щільності гніздового поселення, вікового складу популяцій.

На території Західної та Південної Європи встановлено залежності розміру перших кладок від біотопу (Artemeva, 2006). У Приладож'ї подібні закономірності не виявлені (Blondel et al., 1987). У 2014 році у синиці великої середній розмір кладки достовірно більший (Р < $0,05)$ у нагірній діброві НПП «Гомільшанські ліси», на відміну від субору НПП «Гетьманський» $10,6 \pm 2,34$ проти $9,1 \pm 2,28$, відповідно.

Середній розмір кладки прямо пов'язаний із чисельністю синиці великої та синиці блакитної на контрольованій території, але не залежить від щільності гніздового населення. У Голландії, за даними Х.Н. Клуївера (Kluyver, 1951), популяційні механізми регуляції чисельності, у тому числі скорочення кількості відкладених яєць, починають діяти, якщо щільність гніздового населення становить 40 пар/км².

Таблиия 1

Хронологічна мінливість розміру кладок синиць великої та блакитної на території НПП «Гомільшанські ліси», 2008-2014 pp.

\begin{tabular}{|c|c|c|c|c|}
\hline \multirow{2}{*}{ Рік } & \multicolumn{2}{|c|}{ P. тајог } & \multicolumn{2}{|c|}{ P. caeruleus } \\
\cline { 2 - 5 } & $\mathrm{n}$ & $\begin{array}{c}\text { середній } \\
\text { розмір кладки }\end{array}$ & $\mathrm{n}$ & $\begin{array}{c}\text { середній } \\
\text { розмір кладки }\end{array}$ \\
\hline 2008 & 3 & $9,3 \pm 1,16$ & 6 & $10,7 \pm 2,66$ \\
\hline 2009 & 1 & 9,0 & 7 & $11,7 \pm 1,60$ \\
\hline 2010 & 5 & $11,6 \pm 0,89$ & 2 & 13,0 \\
\hline 2011 & 6 & $10,8 \pm 0,75$ & 2 & 8,0 \\
\hline 2012 & 7 & $12,3 \pm 1,50$ & 8 & $12,8 \pm 1,75$ \\
\hline 2013 & 11 & $11,7 \pm 1,74$ & 3 & $12,3 \pm 1,16$ \\
\hline 2014 & 19 & $10,6 \pm 2,34$ & 2 & 11,5 \\
\hline Разом & 52 & $10,8 \pm 1,93$ & 30 & $11,4 \pm 2,09$ \\
\hline
\end{tabular}

Хронологічна мінливість розміру

Табличя 2 кладок синиць великої та блакитної на території ур. Вакалівщина, 2006-2007, 2009-2014 pp.

\begin{tabular}{|c|c|c|c|c|}
\hline \multirow{2}{*}{ Рік } & \multicolumn{3}{|c|}{ P. major } & \multicolumn{2}{|c|}{ P. саеruleus } \\
\cline { 2 - 5 } & $\mathrm{n}$ & $\begin{array}{c}\text { середній } \\
\text { розмір кладки }\end{array}$ & $\mathrm{n}$ & $\begin{array}{c}\text { середній } \\
\text { розмір кладки }\end{array}$ \\
\hline 2006 & 6 & $8,5 \pm 2,51$ & - & - \\
\hline 2007 & 3 & $10,3 \pm 1,53$ & - & - \\
\hline 2009 & 38 & $9,5 \pm 1,97$ & 3 & $7,3 \pm 3,22$ \\
\hline 2010 & 2 & $6,5 \pm 0,71$ & - & - \\
\hline 2011 & 14 & $10,5 \pm 2,50$ & 1 & 10,0 \\
\hline 2012 & 3 & $8,0 \pm 2,65$ & - & - \\
\hline 2013 & 10 & $11,4 \pm 1,84$ & 1 & 12,0 \\
\hline 2014 & 18 & $9,9 \pm 2,68$ & 1 & 8,0 \\
\hline Разом & 94 & $9,3 \pm 2,33$ & 6 & $9,3 \pm 2,81$ \\
\hline
\end{tabular}


На території НПП «Гомільшанські ліси» найбільша кількість кладок розпочата синицею великою у II декаді квітня (n = 28), а синицею блакитною - у III декаді квітня $(\mathrm{n}=17)$ (табл. 4). В ур. Вакалівщина самки синиці великої почали відкладання яєць у I декаді травня (n = $25)$, а синиці блакитної - у I (n = 2) та II (n=2) декадах травня (табл. 5), тобто значно пізніше, порівняно $з$ попе- редньою територією. У НПП «Гетьманський» більшість кладок синиць великої та блакитної розпочаті у ІІІ декаді квітня ( $\mathrm{n}=8$ та 2, відповідно) (табл. 6). У різні роки протягом сезону розмноження на території НПП «Гомільшанські ліси» розмір кладок синиць великої та блакитної достовірно зменшується, на це вказують також Х.К.П. Крік зі співавторами (Crick et al., 1993).

Мінливість розміру кладок синиць великої та блакитної

Табличя 4 залежно від строків початку яйцевідкладання на території НПП «Гомільшанські ліси», 2008-2014 рр.

\begin{tabular}{|c|c|c|c|c|c|c|}
\hline \multirow{2}{*}{$\begin{array}{c}\text { Строки початку } \\
\text { відкладання яєць }\end{array}$} & \multicolumn{3}{|c|}{ P. major } & \multicolumn{3}{|c|}{ P. caeruleus } \\
\hline & $\begin{array}{c}\text { кількість } \\
\text { кладок }\end{array}$ & $\begin{array}{c}\text { кількість яєць } \\
\text { у гніздах }\end{array}$ & $\begin{array}{c}\text { середній } \\
\text { розмір кладки }\end{array}$ & $\begin{array}{c}\text { кількість } \\
\text { кладок }\end{array}$ & $\begin{array}{c}\text { кількість яєць } \\
\text { у гніздах }\end{array}$ & $\begin{array}{c}\text { середній } \\
\text { розмір кладки }\end{array}$ \\
\hline $11.04-20.04$ & 28 & 309 & $11,2 \pm 1,77$ & 11 & 128 & $11,6 \pm 1,21$ \\
\hline $21.04-30.04$ & 15 & 168 & $11,2 \pm 3,17$ & 17 & 198 & $11,6 \pm 4,32$ \\
\hline $01.05-10.05$ & 5 & 45 & $9,0 \pm 3,94$ & 4 & 40 & $10,0 \pm 2,58$ \\
\hline $11.05-20.05$ & 4 & 25 & $6,3 \pm 3,30$ & 2 & 7 & 3,5 \\
\hline $21.05-31.05$ & 4 & 20 & $5,0 \pm 2,83$ & 3 & 15 & $5,0 \pm 2,65$ \\
\hline
\end{tabular}

Табличя 5

Мінливість розміру кладок синиць великої та блакитної залежно від строків початку яйцевідкладання на території ур. Вакалівщина, 2006-2007, 2009-2014 рр.

\begin{tabular}{|c|c|c|c|c|c|c|}
\hline \multirow{2}{*}{$\begin{array}{c}\text { Строки початку } \\
\text { відкладання яєць }\end{array}$} & \multicolumn{3}{|c|}{ P. major } & \multicolumn{3}{|c|}{ P. caeruleus } \\
\hline & $\begin{array}{c}\text { кількість } \\
\text { кладок }\end{array}$ & $\begin{array}{c}\text { кількість яєць } \\
\text { у гніздах }\end{array}$ & $\begin{array}{c}\text { середній } \\
\text { розмір кладки }\end{array}$ & $\begin{array}{c}\text { кількість } \\
\text { кладок }\end{array}$ & $\begin{array}{c}\text { кількість яєць } \\
\text { у гніздах }\end{array}$ & $\begin{array}{c}\text { середній } \\
\text { розмір кладки }\end{array}$ \\
\hline $01.04-10.04$ & 1 & 11 & 11,0 & - & - & - \\
\hline $11.04-20.04$ & 9 & 86 & $9,6 \pm 3,84$ & - & - & - \\
\hline $21.04-30.04$ & 19 & 201 & $10,6 \pm 2,59$ & 1 & 12 & 12,0 \\
\hline $01.05-10.05$ & 25 & 214 & $8,6 \pm 3,71$ & 2 & 9 & 4,5 \\
\hline $11.05-20.05$ & 15 & 121 & $8,1 \pm 3,11$ & 2 & 18 & 9,0 \\
\hline $21.05-31.05$ & 15 & 64 & $4,3 \pm 3,31$ & 1 & 8 & 8,0 \\
\hline $01.06-10.06$ & 1 & 4 & 4,0 & - & - & - \\
\hline
\end{tabular}

Мінливість розміру кладок синиць великої та блакитної

Таблиия 6 залежно від строків початку яйцевідкладання на території НПП «Гетьманський», 2014 р.

\begin{tabular}{|c|c|c|c|c|c|c|}
\hline \multirow{2}{*}{$\begin{array}{c}\text { Строки початку } \\
\text { відкладання яєць }\end{array}$} & \multicolumn{3}{|c|}{ P. major } & \multicolumn{3}{|c|}{ P. caeruleus } \\
\hline & $\begin{array}{c}\text { кількість } \\
\text { кладок }\end{array}$ & $\begin{array}{c}\text { кількість яєць } \\
\text { у гніздах }\end{array}$ & $\begin{array}{c}\text { середній } \\
\text { розмір кладки }\end{array}$ & $\begin{array}{c}\text { кількість } \\
\text { кладок }\end{array}$ & $\begin{array}{c}\text { кількість яєць } \\
\text { у гніздах }\end{array}$ & $\begin{array}{c}\text { середній } \\
\text { розмір кладки }\end{array}$ \\
\hline $11.04-20.04$ & 5 & 58 & $11,6 \pm 1,52$ & - & - & - \\
\hline $21.04-30.04$ & 8 & 75 & $9,4 \pm 0,92$ & 2 & 21 & 10,5 \\
\hline $01.05-10.05$ & 2 & 20 & 10,0 & - & - & - \\
\hline $11.05-20.05$ & 4 & 27 & $6,8 \pm 2,99$ & 1 & 2 & 2,0 \\
\hline $21.05-31.05$ & 2 & 15 & 7,5 & - & - & - \\
\hline $01.06-10.06$ & 1 & 7 & 7,0 & - & - & - \\
\hline
\end{tabular}

Одним із важливих чинників, 3 яким пов'язують відкладання других кладок, є породний склад деревостану. У хвойних і вічнозелених лісах Західної Свропи другий цикл гніздування птахи починають частіше, ніж у листопадних (Cramp and Perrins, 1993). За нашими даними, у 2014 році у суборі з переважанням сосни звичайної (Pinus sylvestris L.) другий цикл гніздування почали 7,7\% $(\mathrm{n}=2)$ синиць, у широколистяних лісах - близько 4,2\% $(\mathrm{n}=1)$, у діброві нагірного типу - 9,5\% $(\mathrm{n}=2)$. На частоту відкладання других кладок синицею великою у Західній Свропі впливає щільність гніздового населення (Kluyver, 1951). Особини старших вікових груп починають другий цикл розмноження частіше, ніж особини першого року. Проте на частоту біциклії не впливають час початку розмноження популяції та весняна погода.
Дане явище, швидше, пов'язане 3 наявністю достатньої кормової бази у весняний період. Для частоти біциклії важлива сума середньомісячних температур грудня, січня та лютого. Тобто у тепліші сезони птахи будуть готові до розмноження раніше, ніж у холодні, оскільки зимові погодні умови впливають на динаміку чисельності комах, які створюють кормову базу для даних видів птахів. Це підтверджують результати наших досліджень у 2008 та 2014 рр., коли у зв'язку з теплими та ранніми веснами синиці почали гніздування одразу після розподілу по територіях. Своєрідний вплив на появу других кладок у гніздах синиць великої та блакитної створюють зимові погодні умови. Зокрема, у Приладож'ї після теплих зим їх кількість зростала (Artemeva, 2006). 


\section{Висновки}

Синиці починають нестися за стійкого переходу середньодобової температури чере $3+4{ }^{\circ} \mathrm{C}$. Максимальна кількість розпочатих кладок в умовах НПП «Гомільшанські ліси» для синиці великої та синиці блакитної (середній розмір - 12,3 $\pm 1,50$ та 12,8 $\pm 1,75$ яєць відповідно) спостерігається за $+15^{\circ} \mathrm{C}$, зі зростанням якої розмір кладки поступово зменшується.

У Сумській та Харківській областях розмір повних кладок синиці великої $(\mathrm{n}=164)$ варіює від 5 до 15 яєць, що у середньому становить в умовах НПП «Гомільшанські ліси» $10,8 \pm 1,93$, в ур. Вакалівщина $-9,3 \pm 2,33$ та у НПП «Гетьманський» - 9,1 $\pm 2,28$. Для синиці блакитної $(\mathrm{n}=38)$ розмір повних кладок варіює від 5 до 15 яєць, що у середньому становить в умовах НПП «Гомільшанські ліси» 11,4 $\pm 2,09$, в ур. Вакалівщина $9,3 \pm 2,81$ та у НПП «Гетьманський» - 10,5. Аналіз окремо по кожній території показав, що найбільшу частку в умовах НПП «Гомільшанські ліси» у синиці великої складають 11-яйцеві кладки $(10,9 \%)$, а у синиці блакитної - 12-яйцеві кладки $(21,1 \%)$, в ур. Вакалівщина у синиці великої переважають 11-яйцеві кладки (12,7\%), a у НПП «Гетьманський» - 9- та 10-яйцеві кладки (по 3,0\%). Для синиці блакитної в умовах ур. Вакалівщина та НПП «Гетьманський» не виявлено розмір кладки, який би переважав. На території НПП «Гомільшанські ліси» найбільша кількість кладок розпочата синицею великою у II декаді квітня $(\mathrm{n}=28)$, а синицею блакитною - у III декаді квітня $(\mathrm{n}=17)$. В ур. Вакалівщина самки синиці великої почали відкладання яєць у I декаді травня $(\mathrm{n}=25)$, а синиці блакитної - у I $(n=2)$ та II $(n=2)$ декадах травня, тобто значно пізніше порівняно $з$ попередньою територією. У НПП «Гетьманський» переважну кількість кладок синиці велика та блакитна почалі у III декаді квітня.

\section{Бібліографічні посилання}

Artemeva, M.D., 2006. Osobennosti populyatsionnoy ekologii bolshoy sinitsy v taezhnyh lesah Priladozhya [Features of population ecology of the Great Tit in the taiga forests of Priladozhje]. Ornitologicheskie issledovanija v Severnoj Evrazii. Tezisy 12 Mezhdunarodnoj ornitologicheskoj konferencii [Ornithological studies in Northen Eurasia. Theses 12 th to the International ornithological conference]. Stavropol, 44-45 (in Russian).

Blondel, J., Clamens, A., Cramm, P., Gaubert, H., Isenmann, P., 1987. Population studies on tits in the Mediterranean region. Ardea 75, 21-34

Boulton, R.L., Cassey, P., 2012. How avian incubation behaviour influences egg surface temperatures: Relationships with egg position, development and clutch size. J. Avian Biol. 43, 289-296.

Boyce, M.S., Perrins, C.M., 1987. Optimizing great tit clutch size in a fluctuating environment. Ecology 68, 142-153.

Cardillo, M., 2002. The life-history basis of latitudinal diversity gradients: How do species traits vary from the poles to the equator? J. Anim. Ecol. 71, 79-87.

Christians, J.K., Evanson, M., Aiken, J.J., 2001. Seasonal decline in clutch size in European starlings: A novel randomization test to distinguish between the timing and quality hypotheses. J Anim. Ecol. 70, 1080-1087.
Christians, J.K., 2000. Producing extra eggs does not deplete macronutrient reserves in European starlings (Sturnus vulgaris). J. Avian Biol. 31, 312-318.

Christians, J.K., 2002. Avian egg size: Variation within species and inflexibility within individuals. Biol. Rev. 77, 1-26.

Clifford, L.D., Anderson, D.J., 2001. Food limitation explains most clutch size variation in the Nazca booby. J. Anim. Ecol. 70, 539-545.

Cramp, S., Perrins, C.M. (Eds), 1993. The birds of the Western Palearctic. Vol. 7. Oxford University Press, Oxford, New York.

Crick, H.Q.P., Gibbons, D.W., Magrath, R.D., 1993. Seasonal changes in clutch size in British birds. J. Anim. Ecol. 63, 263-273.

Daan, S., Dijkstra, C., Tinbergen, J.M., 1990. Family planning in the Kestrel (Falco tinnunculus): The ultimate control of covariation of laying date and clutch size. Behaviour 114, 83-116.

De Neve, L.J., Soler, J., Soler, M., Pérez-Contreras, T., 2004. Differential maternal investment counteracts for late breeding in magpies Pica pica: An experimental study. J. Avian Biol. 35, 237-245.

Griebeler, E.M., Caprano, T., Bohning-Gaese, K., 2010. Evolution of avian clutch size along latitudinal gradients: Do seasonality, nest predation or breeding season length matter? J. Evol. Biol. 23, 888-901.

Grønstøl, G.B., Blomqvist, D., Wagner, R.H., 2006. The importance of genetic evidence for identifying intra-specific brood parasitism. J. Avian Biol. 37, 197-199.

Hansson, B., Bensch, S., Hasselquist, D., 2000. The quality and the timing hypotheses evaluated using data on Great Reed Warblers. Oikos 90, 575-581.

Haywood, S., 2013. Origin of evolutionary change in avian clutch size. Biol. Rev. 88, 895-911.

Kluyver, H.N., 1951. The population ecology of the Great Tit, Parus major L. Ardea 39, 1-135.

Krist, M., 2011. Egg size and offspring quality: A meta-analysis in birds. Biol. Rev. 86, 692-716.

Lengyel, N.L., Collie, J.S., Valentine, P.C., 2009. The invasive colonial ascidian Didemnum vexillum on Georges BankEcological effects and genetic identification. Aq. Inv. 4(1), 143-152.

Lengyel, S., 2007. Benefits of large broods by higher chick survival and better territories in a precocial shorebird. Behav. Ecol. Sociobiol. 61, 589-598.

Lepage, D., Gauthier, G., Menu, S., 2000. Reprodactive consequeces of egg-laying decisions in snow geese. J. Anim. Ecol. 69, 414-427.

Møller, A.P., Adriaensen, F., Artemyev, A., Banbura, J., Barba, E., Biard, C., Blondel, J., Bouslama, Z., Bouvier, J.-C., Camprodon, J., Cecere, F., Chaine, A., Charmantier, A., Charter, M., Cichoń, M., Cusimano, C., Czeszczewik, D., Doligez, B., Doutrelant, C., Dubiec, A., Eens, M., Eeva, T., Faivre, B., Ferns, P.N., Forsman, J.T., García-del-Rey, E., Goldshtein, A., Goodenough, A.E., Gosler, A.G., Góźdź, I., Grégoire, A., Gustafsson, L., Hartley, I.R., Heeb, P., Hinsley, S.A., Isenmann, P., Jacob, S., Järvinen, A., Juškaitis, R., Kania, W., Korpimäki, E., Krams, I., Laaksonen, T., Leclercq, B., Lehikoinen, E., Loukola, O., Lundberg, A., Mainwaring, M.C., Mänd, R., Massa, B., Mazgajski, T.D., Merino, S., Mitrus, C., Mönkkönen, M., Morales-Fernaz, J., Moreno, J., Morin, X., Nager, R.G., Nilsson, J.-Å., Nilsson, S.G., Norte, A.C., Orell, M., Perret, P., Perrins, C.M., Pimentel, C.S., Pinxten, R., Priedniece, I., Quidoz, M.-C., Remeš, V., Richner, H., Robles, H., Russell, A., Rytkönen, S., Senar, J.C., Seppänen, J.T., Pascoal da Silva, L., Slagsvold, T., Solonen, T., Sorace, A., Stenning, M.J., Török, J., Tryjanowski, P., van Noordwijk, A.J., von Numers, M., Walankiewicz, W., Lambrechts, M.M., 2014a. Clutch size in European secondary hole-nesting passerines in 
relation to nest-box floor area, habitat, geographic location and study year. Methods Ecol. Evol. 5, 353-362.

Møller, A.P., Adriaensen, F., Artemyev, A., Bańbura, J., Barba, E., Biard, C., Blondel, J., Bouslama, Z., Bouvier, J.-C., Camprodon, J., Cecere, F., Charmantier, A., Charter, M., Cichoń, M., Cusimano, C., Czeszczewik, D., Demeyrier, V., Doligez, B., Doutrelant, C., Dubiec, A., Eens, M., Eeva, T., Faivre, B., Ferns, P.N., Forsman, J.T., García-Del-Rey, E., Goldshtein, A., Goodenough, A.E., Gosler, A.G., Góźdź, I., Grégoire, A., Gustafsson, L., Hartley, I.R., Heeb, P., Hinsley, S.A., Isenmann, P., Jacob, S., Järvinen, A., Juškaitis, R., Korpimäki, E., Krams, I., Laaksonen, T., Leclercq, B., Lehikoinen, E., Loukola, O., Lundberg, A., Mainwaring, M.C., Mänd, R., Massa, B., Mazgajski, T.D., Merino, S., Mitrus, C., Mönkkönen, M., Morales-Fernaz, J., Morin, X., Nager, R.G., Nilsson, J.-Å., Nilsson, S.G., Norte, A.C., Orell, M., Perret, P., Pimentel, C.S., Pinxten, R., Priedniece, I., Quidoz, M.-C., Remeš, V., Richner, H., Robles, H., Rytkönen, S., Senar, J.C., Seppänen, J.T., da Silva, L.P., Slagsvold, T., Solonen, T., Sorace, A., Stenning, M.J., Török, J., Tryjanowski, P., van Noordwijk, A.J., von Numers, M., Walankiewicz, W., Lambrechts, M.M., 2014b. Variation in clutch size in relation to nest size in birds. Ecology and Evolution 4(18), 3583-3595.

Møller, A.P., Adriaensen, F., Artemyev, A., Bańbura, J., Barba, E., Biard, C., Blondel, J., Bouslama, Z., Bouvier, J.-C., Camprodon, J., Cecere, F., Chaine, A., Charmantier, A., Charter, M., Cichoń, M., Cusimano, C., Czeszczewik, D., Doligez, B., Doutrelant, C., Dubiec, A., Eens, M., Eeva, T., Faivre, B., Ferns, P.N., Forsman, J.T., García-del-Rey, E., Goldshtein, A., Goodenough, A.E., Gosler, A.G., Góźdź, I., Grégoire, A., Gustafsson, L., Hartley, I. R., Heeb, P., Hinsley, S.A., Isenmann, P., Jacob, S., Järvinen, A., Juškaitis, R., Kania, W., Korpimäki, E., Krams, I., Laaksonen, T., Leclercq, B., Lehikoinen, E., Loukola, O.,
Lundberg, A., Mainwaring, M.C., Mänd, R., Massa, B., Mazgajski, T.D., Merino, S., Mitrus, C., Mönkkönen, M., Morales-Fernaz, J., Moreno, J., Morin, X., Nager, R.G., Nilsson, J.-Å., Nilsson, S.G., Norte, A.C., Orell, M., Perret, P., Perrins, C.M., Pimentel, C.S., Pinxten, R., Priedniece, I., Quidoz, M.-C., Remeš, V., Richner, H., Robles, H., Russell, A., Rytkönen, S., Senar, J.C., Seppänen, J.T., Pascoal da Silva, L., Slagsvold, T., Solonen, T., Sorace, A., Stenning, M.J., Török, J., Tryjanowski, P., van Noordwijk, A.J., von Numers, M., Walankiewicz, W., Lambrechts, M.M., 2014c. Clutch-size variation in Western Palaearctic secondary holenesting passerine birds in relation to nest box design. Methods in Ecology and Evolution 5, 353-362.

Nilsson, J.-Å., 2000. Time-dependent reproductive decisions in the Blue Tit. Oikos 88, 351-361.

Patten, M.A., 2007. Geographic variation in calcium and clutch size. J. Avian Biol. 38, 637-643.

Schaper, S.V., Visser, M.E., 2013. Great tits provided with ad libitum food lay larger eggs when exposed to colder temperatures. J. Avian Biol. 44, 245-254.

Soler, J.J., de Neve, L., Martinez, J.G., Soler, M., 2001. Nest size affects clutch size and the start of incubation in magpies: An experimental study. Behav. Ecol. 12, 301-307.

Tinbergen, J.M., Williams, J.B., 2002. Energetics of incubation. Avian incubation: Behaviour, environment, and evolution (ed. D.C. Deeming), 299-313.

Van Noordwijk, A.J., Van Balen, J.H., Scharloo, W., 1981. Genetic and environmental variation in clutch size of the Great tit Parus major. Neth. J. Zool. 31, 342-372.

Yom-Tov, Y., Geffen, E., 2002. Examining Ashmole's hypothesis: Are life-history parameters of resident passerines related to the proportion of migrants? Evol. Ecol. Res. 4, 673-685.

Надійшла до редколегії 23.10.2014 